\title{
The Future of Social Elderly Care in China: From the Perspective of Service-Oriented Government
}

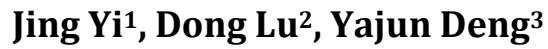 \\ ${ }^{1}$ SWUN Hangkonggang Campus Logistics Group, Southwest University for Nationalities, Chengdu, China \\ ${ }^{2}$ School of Business, Sichuan Normal University, Chengdu, China \\ ${ }^{3}$ School of Social and Political Sciences, Glasgow University, Glasgow, UK \\ Email: carolpiggy@hotmail.com,dlu@sicnu.edu.cn, yajunadela@hotmail.com
}

Received 26 April 2016; accepted 17 June 2016; published 20 June 2016

Copyright $@ 2016$ by authors and Scientific Research Publishing Inc.

This work is licensed under the Creative Commons Attribution International License (CC BY).

http://creativecommons.org/licenses/by/4.0/

(c) (i) Open Access

\begin{abstract}
China today faces the rigorous aging problem. In the traditional sense, the government has the duty to take over all the public affairs including the social elderly care. However, the expanding demand of social elderly care and the limited social resources extremely restrict the process of social elderly care affairs, and in addition, the social elderly care in so-called governmental institutions would lead the inefficiency and even waste of resource. In present, the government plays a role of the core designer and server, namely, the service-oriented government. With explaining the problems now Chinese government faced in theory and practice, this essay tries to put forward some advice to solve the dilemma in social elderly care.
\end{abstract}

\section{Keywords}

Social Elderly Care, Service-Oriented Government, Government Role, Aging Problem

\section{Introduction}

With the social changes in Chinese economic structure, China's population aging process is accelerating. China has been an aging society in 1999. According to the 2010 sixth national census data, the population in mainland aged 60 and over was 178 million, arriving 13.3\% of the total population; population aged 65 and over was 119 million, occuping $8.9 \%$ of the total population. It is reported that the aged population has reached 194 million, and the aging level reached $14.3 \%$ in 2012, and when in 2013, the elderly population reached at 2.02 million and the growth rate was $14.8 \%$ [1]. Compared with developed countries, the aging process in China has a totally

How to cite this paper: Yi, J., Lu, D. and Deng, Y.J. (2016) The Future of Social Elderly Care in China: From the Perspective of Service-Oriented Government. Journal of Service Science and Management, 9, 211-218. 
different political and economic background. In nowadays, the aging process in China has appeared some characters like large quantities, rapid processing, and regional imbalances. That means China has to face a cruel reality which will challenge the economic and social security development.

In ancient China, people always think that the more sons, the more happiness when in an old-age. While changes happen in the population structure and the policies, the scale of family shrinks and the old-care in family decays. People jokes that even raising a son, you cannot be taken care when you are old. According to the prediction, the aging population will ascend at 240 million in 2020 and it will be over 400 million in the year of 2050. In the near future, the aging problem will cause a series of social problems because of the lack of elderly care resource and the policy support. Therefore, the traditional way of elderly care will be taken over by the new social security measures and the social elderly care will flourish in the nationwide. In the report of the party's $18^{\text {th }}$ guiding documents, it stresses that the elderly care is the important part of the public service. The government has the duty to serve the aging populations well and satisfy their diversified requirement. In the meantime, the social endowment service system construction plan (2011-2015) mentioned that China's social endowment service system is combined with three main parts, the household elderly care, the community elderly care and the institution for elderly care. It offers the lifetime care, rehabilitation nursing, spiritual consolation, emergency rescue and other elements related to the elderly care to the all aging individuals. Thus, the Chinese government has deeply aware of the urgency and importance of constructing social endowment service system.

In a word, this essay analyzes the current aging problem which now the society faces and the dilemma it might experience. It chooses a fresh point of view to discuss the problems and tries to raise approaches from both theory and practice aspects.

\section{The Service-Oriented Government Theory and Practice}

The concept of Service Administration was put forward by Ernst Forsthoff in early 1938 [2]. As the rapid development of society and economy in western countries, the citizens had more requires towards the public goods. They demanded that the government should not only manage the public affairs well, but also offered more efficient and diversified service. In China, the concept of service-oriented government develops by the concept of Service Administration. In the Tenth National People's Congress, Premier Wen Jiabao has put forward that the management is service, and we government is a service-oriented government which will service the market, service the society and service the people. However, the concept of service-oriented government has been brought in Party programmatic document officially in 2006. The document stressed that the government would strengthen social management and public service functions. It is reported that the macro plan of service-oriented government construction aims to speed up the administrative reform and provided a service-oriented government system. Moreover, the micro plan is to implement the further promotion of separation in enterprise and government agency in order to build a clean and efficient service-oriented government. In the meantime, the academic exploring in service-oriented government theory model and practice are constantly deepened and strengthened. There are different views and angles towards the service-oriented government concept and practice. Some scholars assist service-oriented government aims to serve the society. The role of government is a service provider rather than a commander. The services provided are not by virtue of the way government officials imagined, but by the market needs of the public. Only customer-driven government can provide public service to meet people's reasonable and legitimate demands [3]. Generally speaking, different government management paradigm is due to the different functions of the government in each historical period and change. In an era of agricultural civilization, the government's function stresses on the management due to the low level of economic development of the market. Thus in that pried of time, it forms as the dominant government. While in the era of industrial civilization, with the rapid economic development, the function of government develops as the intervention in the economy but not political management. Therefore, it is formed as the developmental government. In the era of post-industrial civilization, the distinctive feature is the fast-economic development levels and high-degree of market. It is not necessary for further intervention of government in political and economic aspects. Under this situation, the government should focus on the basic and convenient services to all sectors of society and it should be a service-oriented government. In all, the government management is mainly explained in whether the services meet the demand of social development and it is reflected in the Publicity [4].

From the perspective of government aims, Zhang [5] insists that the vicissitude of government Paradigm is based on the people. No matter how the vicissitude happens, the aim of Chinese government will never change. 
The purpose of government is to serve the people and the social development. Start from the relationship between the government and the citizen, Liu [6] explores that there is an agency relationship between the government and the citizen. The service-oriented government is constructed under the concept of Citizen-based and community-based government and then it provide services to meet the needs of citizens and society. Jiang [7] explains that the feature of the service-oriented government is people-oriented, law-based administration, demand guide and responsible government. From the view of government function, it is said that the most important function in China government is to provide necessary public services and products to citizens and social affairs at this stage [8]. The government can perform as an effective government only if considering citizens needs plenty and offering the fundamental public service and goods [9]. As for the responsibility of the government, Zhu and Sun [10] think that the purpose of government is to manage well, thus offering high-quality service is to reaching a better management and specification. Chen and $\mathrm{Wu}$ [11] assist that the publicity of government determines its fundamental responsibility to provide public services and products to meet the needs of the whole society.

In addition, some criticisms lie on the meaning of service-oriented government. Shen and Guo [12] mention that the so-called reformation in service-oriented government is worth consultation because the understanding of service-oriented government in different levels of government is diversified at present. Obviously, the concept of service-oriented government cannot cover all the aspect of government function and the word serviceoriented government seems to focus on the service of government but weakening the responsibility. Thus it is detrimental to the rational allocation of public resources. The government should be a social-oriented administration no matter when and where, therefore, the word service-oriented government should be judged as a part of social development. The key word service-oriented government cannot be found in almost western literature database while Chinese scholars focus on the service-oriented [2]. It is obvious that the concept and the explaining of service-oriented government reveal the previous situation in social public service needs [9]. Some scholars believe that the principle of service-oriented government coming from the new public management, says steering rather than rowing. But under this pattern, government behavior is easily trapped in the misunderstanding of centralization and decentralization debate while this formulation is relatively static rather than dynamic process throughout the entire history of government reform. It will bring the limitations and one-sidedness. In contrast, the concept of guide-government might be comprehensive and dynamic in line with the course of human history [13].

\section{The Present Situation of Chinese Social Elderly Care}

The development of social elderly care in our country is at a critical point with bottlenecks and opportunities coexist. It is said in $18^{\text {th }}$ CPC report that social elderly care is an important component of the public service which aims to achieve the strategic objectives of a sense of security to meet the multi-level diversification elderly care service needs. It is necessary to accelerate the improvement of the social elderly service system. Recently, China's social elderly care focused on community and institutional service. Although many new social elderly care such as the Housing Endowment, remote endowment, tourism endowment and others are explored and respected by scholars, the development is still subject to geographical and allocation of resources limits [14]. In practice, according to the 2014 National Economic and Social Development Statistics Bulletin, there are 38,000 social service institutions providing accommodations, of which the elderly services are 34,000 . And there are social services bed 5.865 million, including 5.514 million endowment beds. All kinds of shelter and rescue personnel are reached 304.6 million and the elderly personnel are 2.887 million. However, the population over 65 years old has reached1.1883 one hundred million and the service provided by institutions is far behind the pace of demand. In theory research, Wang and Qi [15] believe that the social elderly care has the nature of narrow welfare. It should satisfy all the social welfare. On the contrary, some scholars stand on the view of the generalized welfare which contains both nonprofit and for-profit. For example, Li suggests that the service subjects should not only be one certain group but diversified ones [16]. Furthermore, Li also thinks it should be charged by different service levels because the service charged can be provided by marketing which is not inconsistent with the social welfare. In all, it is clear that we need a framework to support no matter the basic elderly service or the specified elderly service, which requires the government on institutional and strategic direction of the control. However, in this stage of process, it cannot meet the real needs in China's social elderly care. 


\section{Dilemma of Social Elderly Care in China}

In relation to social elderly care, the service-oriented government shall be a server other than a governor in charge of all social affairs. The concept of service-oriented government coincides exactly with the public governance theory put forward by Orstrom [17]. According to her polycentric governance theory, a government shall not arrogate power to itself in dealing with public affairs, but render public products and public service work to social organizations, enterprises and other social affair participants. However, the government cannot stay out of the market mechanism but shall play core subject in polycentric governance. Namely, the government shall be in charge of establishing directional and macro policies and plans in association with development of public affair, and shall provide social associations with process service for social service and products. Considering that China's social elderly care started relatively late, the development of social elderly care is hampered in terms of nature positioning and system design. Currently, the participants of social elderly care industry in China mainly include social enterprises, individual family and government agency. This Chapter will set forth the difficulties encountered by participating subjects with respect to social elderly care.

\subsection{Dilemma of the Social Enterprises}

From the social enterprises, the reason why social elderly care cannot witness a rapid and considerable development is that: 1) the social elderly care mode implemented by social enterprises is single, mostly being institution for old-age care. At present, many regions have explored new social elderly care modes, but these modes cannot widely be spread and applied due to the limitation of regions and financial capacity towards the target audiences [18]; 2) The concept and definition of social enterprise has not been localized fully. Being an imported concept, the social enterprises have not definite status and fail to be supported by favorable systems and policies in terms of operation. Due to the lack of definite guidance and reference, the operation of social elderly care enterprises is not transparent sufficiently, especially that their financial management systems are not of clearness and soundness, and cannot be supervised by the public and the society. As a consequence, the public has low confidence in putting funds into social elderly care industry which directly resulting in severe shortage of social elderly care funds; 3) low degree of specialization and shortage of human resources. According to Zheng [19], China's social enterprises participating into social elderly care are insufficient and have lower degree of specialization. The existing 15,000 social elderly care enterprises have an employee size of 200,000, far from satisfying the current elderly care demands. Meanwhile, most of relevant practitioners are between 40 and 50 years old, and their educational and specialty quality is required to be improved. Additionally, a large number of volunteers are not professionals participate into the social elderly care due to the insufficient funds. Xiao and Chen [20] respectively carry out questionnaire survey to the nurses from state-run elderly care institutes and private elderly care agencies, and make Mann-Whitney inspection and dual-sample Kolmogorov-Smirnov inspection. It is concluded that the average age of the nurses who serve the exiting social elderly care agencies in China is 43.8 years, and those who serve private aged care service agencies are 3.8 years higher than the average age, and 7.4 years higher than those who serve state-run social elderly care institutes. Furthermore, $73.9 \%$ of the nurses who serve private social elderly care agencies only received education lower than junior middle school, $13.8 \%$ higher than those who serve state-run social elderly care institutes; only $4.5 \%$ of nurses who serve private social elderly care agencies are in college degree or above, $8.2 \%$ lower than those who serve state-run social elderly care institutes. Due to the gap in terms of age and education degree, the practitioners who serve social elderly care agencies fail to achieve sound effect from technical training and further education.

\subsection{Dilemma of the Individuals and Family}

As for the individuals and family, China's traditional elderly care mode is home care and such deep-rooted ideology and tradition will not be changed for a short term. Through previous researches, some scholars find at most of the elder people do not accept the social elderly care agencies, and they do not believe that satisfied service can be provided by social agencies. Therefore, they are unwilling to select any social elderly care rather than stay home [21]. Wang and $\mathrm{Ni}$ [22] adopt the research on samples taken in Hangzhou City,. They find that 78.61\% if the old expressed their support in community elderly care policies after they have good understanding of the three basic social elderly care modes: household elderly care, community elderly care and institution elderly care. However, when in making actual decisions, the elderly care of many old people is jointly assumed by 
government agencies and their homes due to good benefits offered by state-owned institutes under China's tradition systems. Additionally, insufficient individual pension fund is an important factor hampering selection of social elderly care. It is pointed out that the expenses as required by current elderly care are difficultly maintained only by pensions [23].

\subsection{Dilemma of the Government}

A government plays a critical role in development of social elderly care industry. The ideology of support by government and participating by market for social elderly care is not carried out effectively, and the respective responsibility is not clarified, the government is in function dislocation, offside and omission in the field of social elderly care. Ji [24] from the perspective of the agency theory, puts forward that transformation from single agency to diversified agencies is favorable for improvement of elderly care efficiency. He announces that service arranging shall be separated from the direct production. In China's social elderly care, most of service is offered and arranged by relevant governmental agencies and produced directly by such agencies, which results in the inefficiency. Furthermore, the information asymmetry and shortage of the approach to express demands are also puzzles the-aged at current stage. Yu el al. [25] think that the social elderly care fails to obtain support from improved systems and laws at present. Particularly speaking, an improved national elderly care service system is composed of institutional elderly care and residual elderly care, the latter may be provided by society to meet the demands of the aged individual who has the capability and is willing to pay. However, in China, the two elderly care service have not been distinguished thoroughly. Most of the service is funded and managed by the government that hampering the diversification of elderly care and also burdening the government itself. On the one side, the government actively encourages the aged to select diversified elderly care because of the rigorous aging problem. But on the other side, seldom social enterprises are willing to participate into the elderly care service in case various entering policy barriers and strict administrative governance [26]. Zhu also deems that the non-standardized social elderly care is due to the lack of reasonable and legal assessment mechanism on specialty and supervision process [27].

In a word, the key factor hampering sustainable development of social elderly care reflects as two aspects: first, there is no policy that can clarify the service nature and support allocation of relevant resources; second, the social elderly care policy is formulated in a stylized manner not based on actual interaction process. Therefore, the supply-demand relationship is dislocated due to less consideration of historical factors of social development and actual demands of the target audience.

\section{Approach of Social Elderly Care in Perspective of Service-Oriented Government}

A government, as classifier role, shall undertake irreplaceable responsibilities. On one hand, the government shall position and render public service and products in a macro manner; on the other hand, the government shall provide social organizations engaged in public service with support in terms of policies and systems. In relation to social elderly care, the government shall give a full play to the roles of server and leader.

\subsection{Enhance the System Contribution}

Establishment the system contains two aspects. Firstly, establish guided policies and favorable policies. The development of social elderly care requires participation and support from various industries and sectors, including medical, real estate and housekeeping industries. In China, the government excessively interferes with the service matters that which leads relevant enterprises obtain less and social force is not interested in participating into the social elderly care. Thus, the government shall provide preferable policies and support with respect to land, taxation, and allowance on the social elderly care. Secondly, establish the social elderly care classification standards and supervision policies. In China, the social elderly care institutions compete fiercely and illegally because of the ambiguous service standards and legal relationship [28]. The charges of local elderly care agencies mainly include bed fee, nursing expenses and board expenses. In general, the charge standards usually follow territorial principles, and the charges of welfare or semi-welfare elderly care agencies are required to be reviewed and approved of local pricing authority. As for the Profit-seeking elderly care agencies, they priced and charges by the market-adjusted pricing. Under this case, the charge standard is unified, the access threshold is inconsistent and the indicator assessment is non-standardized [29]. At present, the policies in elderly care service 
are not formulated in detail and substantially. Challenged by aggregation of aging tendency, rapid growth of old population and change in family structure, the demands for elderly care decrease but the government only can invest limited resources into it. Therefore, the government shall encourage and guide the private and foreign capital to the construction of institutional elderly care.

\subsection{Expand the Fund Sources}

Fund resources may be expanded from two levels: first, the governmental shall undertake some of social elderly care funds indeed. At present, China's elderly care industry is in early development stage, a large amount of upfront costs and arrangement are indispensable. Zhao and Zhou [30] point out that many of employees from grass-roots community organizations take increase of community income as their primary missions and focus on earning extra money due to less governmental allowance, insufficient community funds and limited social fund raising and sub-district self-raising capability, but make less effort to think about and find a solution for development of community elderly care. Some scholars believe that the government fails to prepare standardized and permanent provisions with respect to preferable policy support and fund allocation [31], which involves the second level of expanding fund resources. Expanding fund resources does not mean that the government will undertake all of funds and allowances as required by social elderly care, but shall provide social organizations and enterprises with elderly care financing and investment environment under in the manner of the old saying that it's better to teach a man fishing than to give him fish. According to the provisions of Opinions of the State Council Concerning Accelerating Development of Elderly care Industry (G.F. [2013] No. 35), the nursing service rendered by elderly care agencies shall be exempted from business tax. According to Clause VIII of Provisional Regulations of the People's Republic of China on Business Tax, the nursing service, singles matching and funeral service provided by child-care center, kindergarten, old people's home and disability welfare institutions shall be exempted from business tax. According to Circular of Ministry of Finance and State Administration of Taxation on Exemption of Business Tax on Employee-based Domestic Services (C.S. [2011] No.51), the domestic service provided by employee-based housekeeping personnel from housekeeping service enterprises shall be exempted from business tax from Aug. 1, 2011 to Sep. 30, 2014. According to the above, China’s social elderly care policies are not substantiated at present stage, limiting the provider of service to elderly care agencies only, but ignoring diversified modes as required by diversified development of social elderly care, and failing provide standardized service modes and policy support. Furthermore, only a few rules for elderly care are set forth in the definition of housekeeping service, and the tax preference on business tax is only provided to non-profit welfare institutions. Therefore, it is urgently to spare no effort to explore the possibility to expand fund resources.

\subsection{Narrow the Gap between Service Supply and Demand}

At present, the elderly care mainly focuses on old widowers, widows or the aged who are independent in economic capability and selection ability, but pay less attention to ordinary old people [32]. Furthermore, the service contents mainly daily care but less spiritual consolation and is mostly reflected by recreational and sports activities which only can be enjoyed by the old people with sound self-care ability. Wu [33] analyzes the elderly care demand and supply of China's elderly care institutions and then concluded that the demand for elderly care is urgent, but the occupancy rate of the institutions is seldom. The reason is that the existing elderly care institutions only provide basic daily care service but pay less attention to other important factors for the demand of the aged. Therefore, it is crucial for development of elderly care industry to thoroughly investigate and find out the approach to motivate social resources to meet supply-demand of elderly care.

\subsection{Make More Efforts on Establishment of Service Team and Cultivation of Professionals}

Community elderly care practitioners are composed of full time/part time employees and volunteers. Full time employees usually are the workers of community organization designated by the competent governmental agency that who do not receive any specialty training. Therefore, they can provide daily housekeeping service only, but not provide professional medical care and spiritual service. Obviously, it would fail to meet the multi-level and diversified service demands of the aged individuals [34]. However, competent professionals are unwilling to serve the community organizations due to the low income that which deteriorate the dilemma of 
community professional elderly care [30]. In China, some provinces and municipalities have successively introduced policies concerning cultivation of social workers. Take Chengdu City for instance, the Detailed Measures for Promoting Employment of Elderly Care Talents was issued in July 2015, which stipulating colleges and universities to set up elderly care specialties and to develop social work service practice with relative organizations. In addition, more attractive salaries and remunerations shall be paid to social work talents and the same policies concerning practicing requirements, registration, appraisal and title assessment as medical and welfare organizations shall be applicable to the doctors, nurses, rehabilitation physicians, rehabilitation therapists and social workers serving the aged. At present, the most important thing is to link the practice with policy. The key reason for shortage of social work talents is that the public holds different attitudes upon the social elderly care. Most of people think that the practitioners who are engaged in social elderly care are inferior to others because the work requires no technique or skill. Influenced by these views, many graduates in relevant majors prefer to select other work rather than their specialty. Therefore, the government shall make more efforts to publicize recognition and acceptance of social elderly care. It is also the government's duty to cause the public to be aware of importance of social elderly care by the manners of internet propagation and media publicity. Only in this way, it would change the public's bias on elderly care and improve enthusiasm to the participators to vote into elderly care industry.

\section{Conclusion}

The social elderly care in China develops with both challenge and hope. As for Chinese special situation, the social elderly care will be a trend in around the country because of the global aging problem. On the one hand, the social elderly care could not develop only by the marking rules without governmental intervention because of the faulty policies and elderly care system. On the other hand, excessive intervention of government will lead not only the financial burden but disorder competition. In present, the government aims to be as a guider and a server in theory research. It is still a long run for Chinese government to find that how to be a social affairs guider and a service-oriented server.

\section{Funding}

This study was funded by the Fundamental Research Funds for the Central Universities (Grant No. 2016SZYQN52), the Research Foundation of Education Bureau of Sichuan Province (16SA0014).

\section{References}

[1] Jiang, X. and Du, P. (2013) Report on China’s Population Ageing and the Elderly Welfare Facilities. China Renmin University Press, Beijing.

[2] Gao, X. and Wang, L. (2009) Principles of Service-Oriented Government. Renmin Press, Beijing.

[3] Chen, G. (2007) Good Governance: The Model Innovation of China’s Local Government. Zhejiang University Press, Hangzhou.

[4] Zhao, W. and Zhang, Q. (2014) Reflection and Reconstruction of the China's Social Security Governance System on the Pattern of the Service-Oriented Government. Seeker, 8, 103-106.

[5] Zhang, K. (2000) The Concept of Limiting the Size of Government. Administrative Tribune, 4, 7-13.

[6] Liu, X. (2002) The Service-Oriented Government: The Target of China’s Government Reform in the Context of the Economic Globalization. Chinese Public Administration, 7, 5-7.

[7] Jiang, X. (2007) The Research on the Service-Oriented Government Constructing: The Citizen Participation in the Process of Constructing Service-Oriented Government. Social Science Research, 4, 1-7.

[8] Chi, F. (2006) A Comprehensive Understanding of the Basic Meaning of "Public Service-Oriented Government". People’s Tribune, 5, 14-15.

[9] Li, J. (2004) Public Service-Oriendted Government. Peking University Press, Beijing.

[10] Zhu, G. and Sun, T. (2005) Regulation-Service Type Local Government: Its Orientation, Connotation and Construction. Journal of Renmin University of China, 1, 103-111.

[11] Chen, G. and Wu, S. (2009) The Public Service Orientation of the Responsible Government. Social Science Front, 4 , 196-201.

[12] Shen, Y. and Guo, Q. (2006) From the "Public Service-Oriented Government” to the "Social-Oriented Government". 
Productivity Research, 10, 112-114.

[13] Zheng, J. (2013) Understanding China Road from Government Function Perspective: A Study on the Rise of GuideOriented Government Function Model. Journal of Nanjing Agricultural University (Social Science Edition), 4, 97-103.

[14] Chai, X. and Jiang, X. (2004) House Sales for Pension: One Kind of New Ideas Proposed for the Elderly Care Issue. Zhejiang Social Sciences, 1, 150-155.

[15] Wang, S. and Qi, X. (1999) Community Support Is the Best Carrier Assist the Family Elderly Care Service. South China Population, 2, 29-33.

[16] Li, X. (2008) The Research Review of Community Elderly Care Service in China. Social Science in Ningxia, 1, 42-46.

[17] Ostrom, E. (1986) An Agenda for the Study of Institutions. Public Choice, 48, 3-25. http://dx.doi.org/10.1007/BF00239556

[18] Deng, H., Tu, T. and Xiong, Y. (2015) Thinking on the Lack of Social Enterprises Participating in Community Pension Service. Wuhan University Journal (Philosophy \& Social Sciences), 1, 109-115.

[19] Zheng, L. (2015) Dilemmas of Social Organization's Involvement in Social Service for Old People and Strategies Choice: A Practice Analysis Based on Tongling City of Anhui Province. Journal of Changchun University, 3, 86-90.

[20] Xiao, Y. and Chen, T. (2013) The Optimization of Service Members in Private Pension Institutions. Journal of Sichuan University of Science \& Engineering (Social Sciences Edition), 2, 29-33.

[21] Yang, Q. and Luo, X. (2014) Research on Issues of Government Purchase Home Care Service: Based on the Perspective of New Public Service Theory. Journal of Changchun University, 5, 581-584.

[22] Wang, P. and Ni, N. (2011) The Plight of the Community Home Care Services Runnning Dominated by the Government: An Analysis Based on the Four Communities in Hangzhou. Zhejiang Academic Journal, 6, 194-200.

[23] Zhang, Y. and Yan, J. (2015) The Status, Problems and Public Policy Selection of Elderly Care Service System in China. Contemporary Economic Management, 1, 51-56.

[24] Ji, P. (2013) The Analysis of the Main Body of Supply Relationship in Social Elderly Care Service: Based on the Agency Theory. Social Science Front, 6, 184-189.

[25] Yu, J., Jin, L. and Qu, Z. (2012) The Construction of Private-Run Community Care Institution for Old People and Government's Responsibilities: A Case Study of Shangcheng District, Hangzhou. Zhejiang Social Sciences, 11, 76-83.

[26] Gao, C. (2015) Social Enterprises and the Supply of Elderly Care Service in China. Social Science Research, 3, 115120.

[27] Zhu, X. (2014) On Local Legislation of Old-Age Service System in the Context of Population Aging: Ningbo as an Example. Scientific Research on Aging, 3, 55-64.

[28] Zhang, Y. (2008) Summarizing Studies on Social Service Institutions for Elderly in China. Journal of Social Work, 10, 4-7.

[29] Jiang, X. and Zheng, Y. (2013) Analysis on the Main Source of Livelihood and Economic Security of the Chinese Elderly. Population Journal, 2, 42-48.

[30] Zhao, C. and Zhou, Y. (2011) On Old-Age Care Patterns in Urban Communities: On Problems Involving the Care for Old People in Urban Communities. Social Science Journal of Universities in Shanxi, 2, 44-46.

[31] Wang, J. (2008) Social Support of the Home Care for the Urban Elderly. Social Scientist, 4, 110-113.

[32] Yang, H. (2008) The Situation and Development Strategies for the Community Elderly Service in Anshan City. Liaoning Economy, 10, 26-27.

[33] Wu, M. (2011) Research on the Development of Bursing Home Care: Demand and Supply. Economic Science Press, Beijing.

[34] Bian, W. and Qin, Y. (2005) Issue and Countermeasure of City Community Service in Heilongjiang Province. Business Economy, 9, 7-9. 